R. Htstórta, Sao Paulo, n. 127-128, p. 9-35, ago-dea/92 a jan-jul/93.

\title{
EFEITOS DE UMA EPIDEMIA DE VARIOLA EM TAUBATÉ - (1873-1874)
}

\section{Cristina Soto *}

\begin{abstract}
RESUMO: Tentando compreender a contradiçáo detectada entre as medidas aplicadas pelas autoridades no combate a uma epidemia de varfola surgida em 1870 no municfpio de Taubatt e as camemoraghes subsegientes, o artigo vai desvendando os jogos de interesses locais, a crescente importincia dos critérios sanitários na orientaçăo da polftica municipal, as propostas perante o temor que a doença provoca, as resolugobes destinadas a neutralizar os conflitos derivados da epidemia e o processo do construçáo de uma versáo oficial dos fatos. Da interligaçáo destes fatores, extrai o significado do econtocido.
\end{abstract}

PALAVRAS-CHAVE: Epidemia, Vale do Parafba, Higiene, Varfola, Urbanizacto.

\section{O INÍCIO DA EPIDEMIA: INCIDÊNCIA E TRATAMIENTO}

Em 12 de outubro de 1873 deu-se em Taubate um caso de variola, marcando o infcio de uma epidemia que iria durar 3 meses.

Quando em 10 de agosto de 1874, ante a existencia de um único doente, se declarou oficialmente finalizada a epidemia, as autoridades municipais e médicas proclamaram sua satisfação ao fechar o que consideraram um triste capítulo da história do Município, ao mesmo tempo que se congratularam pelo triunfo alcançado.

A epidemia acabou, deixando atrás de si um saldo aproximado de $\mathbf{4 2 3}$ mortos. Deixou também sequielas de outra índole e que não finalizaram tão cedo. Durante o seu transcurso desenvolveu-se uma sćrie de mecanismos que iriam ter continuidade no tempo.

- Pós Graduanda em Histótia FFLCH/USP. 
SOTO, Cristina Eleitos de uma epidemia de varfola em Taubaté -(1873-1874).

No més de outubro de 1873 , já se tinha notícia em Taubaté da existência de uma epidemia de varíola nas províncias do Rio de Janeiro e São Paulo, instalada inclusive em cidades próximas do Vale, como Queluz.

Segundo relatório apresentado à Camara Municipal pelo médico Antonio Teixeira de Souza Alves, nesse mesmo mes, foi detectado o primeiro caso em Taubaté. Tratava-se de um jovem negociante que, de volta da Corte e ao passar pelos lugares afetados, contraiu a doença. Era uma varíola suave e a cura foi atingida em pouco tempo. Mas dias depois apareceram outros dois casos na sua residencia e mais alguns surgiram na mesma rua, a rua Direita, em novembro, estendendo-se pelo quarteirão.

A doença começou a adotar proporçōes epidémicas e, no mes de dezembro, já eram numerosos os atingidos.

Na realidade, a existéncia de varíola era muito anterior; já em janeiro de 1873 a Camara afirmava ao Governo Provincial terem ocorrido "alguns casos funestos" no Munić́pio e solicitava recursos, precisamente "para acudir à pobreza em caso de invasão de epidemia de bexigas"1. Algumas "laminas de pus vacinio" foram também solicitadas em 27 de outubro mas, como os primeiros casos foram considerados benignos, fora esta medida isolada, nenhuma outra foi adotada oficialmente, até se produzir a "invasão" e se estabelecer "definitivamente entre nós" ${ }^{2}$, isto $\varepsilon$, até caracterizar-se uma situaçăo de epidemia. Foi então que as autoridades municipais recorreram ao médico da Comarca, Dr. Souza Alves, que resolveu criar um hospital para o tratamento gratuito dos pobres.

Até esse momento, o tema da epidemia ocupava um lugar secunđário nos debates dos vereadores, sendo mais um ítem, entre outros, na ordem do dia. Mas, à medida em que se desenvolvia e se agravava o processo, o tema começou a aparecer com maior insistencia. Era apresentado praticamente em todas as reuniōes, a partir de maio, coincidindo com o auge da epidemia. Mas em momento nenhum foi realizada uma sessão extraordinária para tratar do tema com exclusividade.

A decisão de encarregar o médico, Dr. Souza Alves, do combate à doença como diretor do hospital, constituiu a principal providencia tomada pelas autoridades municipais. $O$ resto das medidas se reduziu à solicitação de

1 Aras da Cámama de Taubaté, 1869-1879, Ed. Félix Guisard Filha, Sáo Paulo, Empresa Ed. Unjversal, 1944, ano 1873, p.116.

2 Relatório da epidemía de vartola apresenfado a Câmasa Municipal, pelo ilustre e fistinto médico Sr. Doutor Antorio De Souza Alves, em 11 de setembro de 1874, Taubaté, impresso nas oficinas de O Panlista, 1874, p.4. 
R. IItstórta, Sāo Paulo, n. 127-128, p. 9-35, ago-dez/92 a jan-jul/93.

fundos para a manutenção do hospital e a algumas medidas indiretas, devidas, sobretudo, à iniciativa do delegado de polícia e ex-vereador Joaquim Pires Dias: reformulaçāo do código de posturas, aumento em 15 ou 20 do número de policiais, ataques aos curandeiros, organização do cemitério e dos enterros, regulamentação sobre o bater dos sinos, normalização do abastecimento de produtos alimentares e controle da imprensa.

Ante a ausência de um hospital municipal e a desativação do lazareto fora da cidade, escolheu-se um antigo hospital pertencente à Ordem Terceira de São Francisco de Assis, cujo prédio fora cedido à Camara pelo seu Ministro, o Capitāo Caetano José do Amaral. Crescendo o número de doentes, mudaram-se, em fevereiro, ao Convento de Santa Clara, apropriado por ser "altamente colocado, vasto e espaçoso" ${ }^{3}$. Lá permaneceram até o dia 10 de agosto quando, com poucos doentes (4), transferiram-se para um prédio no "Moinho", doado pelo Sr. José Benedito de Mattos.

o Capitão Caetano José do Amaral, nomeado Fornecedor pela Camara, atendia às necessidades materiais enquanto o farmacêutico, Joảo Rodrigues de Souza, providenciava os medicamentos, chegando a aviar mais de 2.000 receitas. Os serviços prestados por ambos, assim como os do diretor, foram gratuitos. Para cobrir as despesas hospitalares foram doados 4 contos e 500 mil réis pelo Chefe de Polícia da Província. Tres contos e 500 mil réis angariaram-se numa subscrição pública na Corte e 250 mil réis em outra, aberta em Caçapava; um conto de réis foi obtido entre os fazendeiros de Taubaté, a pedido do Presidente da Camara.

A organização do hospital e o seu funcionamento ficaram a cargo do Dr. Souza Alves, seu diretor, que abandonou a antiga estrutura do hospital da Ordem Terceira e criou um novo esquema, seguindo um critério hierárquico de organização e poder. No topo, o Diretor era o único com capacidade de decisão, tanto com respeito ao tratamento dos doentes, quanto no aspecto administrativo: geria a contabilidade, dirigia a reorganizaçäo espacial do hospital, a distribuição de leitos e pacientes, governava os empregados e determinava-lhes as funçōes e atividades. Um enfermeiro, pessoa de toda confiança cuidadosamente selecionada, se encarregava de transmitir e fazer cumprir as ordens provenientes da direção, fiscalizar e vigiar o trabalho dos seus subalternos e administrar os remédios aos doentes. Aos empregados, pessoal não especializado, competia fazer os curativos, os serviços domésticos e cuidar dos doentes seguindo estritamente as normas do médico. A

3 idem. 
SOTO, Cristina. Efeitos de uma epidemia de varfola em Taubaté - (1873-1874).

equipe se completava com um religioso que prestava a sua assistencia, onde a medicina se manifestava insuficiente, "alertando ao moribundo e consolando os aflitos" ${ }^{4}$.

Os afetados pela doença, abrigados e comodamente instalados, eram levados ao hospital num carro, seguindo as "ruas extremas". Aqueles que ofereciam resistencia eram conduzidos com a ajuda policial. No hospital, os doentes eram classificados, isto é, separados seguindo vários critérios ordenatórios e distribuídos pelo espaço hospitalar. Refletindo esta divisão eram repartidos por sexo, por idade, pela gravidade da doença e por quantidade, procurando colocar um número reduzido de leitos em cada sala. No Convento, as mulheres situavam-se no melhor lugar, ou seja, no mais espaçoso - -as celas -; as crianças eram cuidadas noutra sala; os convalescentes, separados dos moribundos, "afim de que a morte de uns não amedrontasse os outros" também eram isolados dos que só estavam em observação. As salas deviam ser desinfetadas sem cessar, os leitos dispostos "na melhor ordem possível com a decencia e asseio reclamados" ${ }^{6}$. Acomodados nestas condiçōes, eram visitados diariamente pelo doutor.

Também o tratamento aplicava-se de um modo diferencial, dependendo de uma outra classificação dos doentes, em função da sua maior ou menor resistencia à doença, do tipo de variola que sofriam e das suas transformaçôes. Assim, aos "robustos', "sangürneos, "fortes" e "vigorosos" contrapunham-se os "idosos", "fracos, cachéticos e debilitados", aos jovens, as crianças e os velhos, aos homens, as mulheres...

As crianças e os velhos eram mais sensíveis à moléstias intestinais e convulsōes, as mulheres sofriam numerosas complicaçōes nos orgãos genitais (pústulas, gangrenas), retençōes de urina, hemorragias e abortos prematuros, quase sempre mortais. No entanto, em todos os tratamentos seguia-se - mesmo critério clínico, baseado no princípio de que não era possível prever, reduzir a duração ou interromper o curso da doença. Era melhor deixá-la transcorrer no seu ritmo, sem interrupção.

4 idem.

5 Relntorto, op. cit., p.5.

6 idem. A enfise na limpeas e a procura de lugares espacosos eram dois elementos de que cos pobres careciam no seu cotidiano e a cuja falta o medico atribula a propagacto ha doença. Por outro lada, o ssseio (fisico) e a docência (moral) eram sinônimos e indissocióveis na concepço do medico. O tratamento baseava-se tamberm na identificaçáo entre doença, pobreza, sujeira, por um lado, e scciabilidade, apetite, asseio e satide por outro. 
R. Htst6rta, Så Paulo, a. 127-128, p. 9-35, ago-dez/92 a jan-jul/93.

Por isso o tratamento era dirigido à cura dos efeitos colaterais e para "combater os sintomas"7. Como alfvio à dor receitavam-se as preparaçóes opiáceas e os xaropes calmantes; as implicações gástricas eram combatidas com purgativos; as pústulas nas pálpebras com pomada mercurial; outras pústulas nas mãos, pés, nariz, com sulfato de quinina, sal e infusáo de camomila; a sede com limonada; o delírio com preparaçōes opiáceas, água de louro, de cereja e tintura de beladona; as convulsóes com estrato de beladona; a conjuntivite com "lavagens emolientes"; as hemorragias com adstringentes, opiáceas e sulfato de quinina; outros remédios desta fndole eram aplicados na laringite varilosa, contra a tosse, as ulcerações, os ganglios linfáticos, a febre e a gangrena.

Essas medicações complementavam-se com os cuidados higienicos (banhos, troca de roupa de doente e de cama), o regime dietético, composto de caldos e mingaus, café ou mate, biscoitos, canja de galinha, marmelada e, para os mais debilitados, leite, ovos, pão e vinho.

Para o seu tratamento, o Dr. Souza Alves recolheu informaçōes e remédios provenientes das mais diversas fontes e procurou comprovar a sua eficácia aplicando-os nos doentes.

Dos experimentos feitos o doutor deduziu que alguns (os que năo produziam resultados positivos) eram fruto da ignorancia e do charlatanismo, como era de "se esperar'. Os que, pelo contrário, resultaram excelentes, foram adotados para fazer parte de seu saber médico. Entre eles se incluiam numerosos remédios baseados em ingredientes de plantas autóctones. Como ele mesmo manifestava, a variedade e riqueza nacionais em questão de plantas com propriedades terapéuticas era imensa e devia ser aproveitada. Reconhecia, assim, a existência de um conhecimento de plantas medicinais na cultura e práticas das pessoas do lugar. Mas isso não significava uma concessáo aos curandeiros, recoletores e vendedores de ervas e, em geral, às pessoas que as conheciam e as usavam costumeiramente, as quais, pelo contrário, eram desqualificadas em todas as oportunidades.

Além das soluções populares apropriadas, os tratamentos baseavam-se em conhecimentos médicos aprendidos no curso universitário, através da leitura, experiéncia e troca de impressões com outros colegas. Mas este conhecimento médico não era homogeneo ou único, nem sólido, fechado ou definitivo. Existiam vários tratamentos assentados em diferentes concepções. O Dr. Souza Alves se posicionava num lugar intermediário, entre um tipo de

7 idem. 
SOTO, Cristinn. Efeitos de uma epidemia de varfola em Taubate - (1873-1874).

medicina baseado na aplicação de sangrias e uma corrente mais recente que rechaçava totalmente o seu uso. Consiđerando a sangria uma solução antiga, fundamentada na ignorancia e utilizada excessiva e abusivamente no interior, reconhecia, entretanto, a sua utilidade em determinados casos (não para a variola), "respeite-se o sangue, mas saiba-se apreciar as indicaçöes formais em que é a sangria reclamadan ${ }^{8}$. Também aprovava o uso da vacina frente àqueles "medicastros que com suas autorisadas opiniōes procuram desprestigiar as glorias do immortal Jenner"

Portanto, năo apoiava as rupturas com o passado, nem a repetição conservadora de formulas antigas. Defendendo a renovação da prática e do saber médico, ele mesmo ensaiava no hospital uma medicação nova para as hemorragias.

Em resumo, sua terapêtica reunia diversas tendencias e culturas e ia se construindo com a própria experiencia visando, não curar o doente, mas sim fazer menos penosa a sua convalescéncia, atacando todas as moléstias indiretas provocadas pela varíola. Para esta só existia um procedimento eficaz de cura: a inoculação do vírus no afetado.

A vacina era aplicada na Europa com éxito, desde o século XVII, sendo bem conhecida pelo Dr. Alves e pelas autoridades municipais. No entanto, so foram vacinados 45 dos 288 doentes do hospital $(15,62 \%)$. No começo da epidemia, a vacina foi solicitada ao Governo Provincial, mas não parece ter havido resposta. Só no dia 26 de junho de 1874 a Secretaria do Governo Provincial remeteu um exemplar das instruções "para as pessoas não profissionais conhecerem e propagarem a vacina, extrair e conservar a mes$\mathrm{ma}^{\mathrm{n}}$, que a Camara mandou publicar.

Ao mesmo tempo que, a pedido dos poderes públicos, organizava o hospital, o Dr. Souza Alves atendia outros afetados pela varíola nas residências e na sua "clínica civil"(92). O tratamento não pareceu ter sido exatamente o mesmo do hospital, pois, quando coincidia, ele deixava constar o fato no relatório, como no caso do uso de uma "substancia vermelha que cobre as

8 idem.

9 Jenner, ma passagem do seculo XIX faz importantes observagóes sobre a prática da vacina, que contribuem para disseminar este procedimento e o controle da doença.

10 Atas da Câmara de Taubaté, 20 de jultho de 1874, p. 174. Foi em 1819 que o governo da Capitania de Såo Paulo crica um instituto para a preparaçáo da vacina e se preocupou com a sua divulgaçâ, solicitando aos vigários que promovessem sua aceitaçåo, pelo púlpito. Marcllio, Maria Luiza, A Cidade de Säo Paulo. Povoamento e Populaçãa, 1750-1850, Sto Paulo, Livraria Pioneim Editora, EDUSP,1974. 
R. Histórta, Săo Paulo, n. 127-128, p. 9-35, ago-dez/92 a jan-jul/93.

sementes do urucún, aplicada para prevenir o aparecimento de pústulas nos olhos.

Também alguns dos doentes foram atendidos pelo Dr. Barbosa (148) e outros (300) preferiram os serviços nāo gratuitos de facultativos, ou decidiram não se tratar, ocultando a doença.

Os que morriam no hospital cram colocados num caixão fechado e conduzidos de carro até o cemitério especial dos variolosos, longe das jazidas familiares, onde eram sepultados, poucas horas depois, a mais de 10 palmos de profundidade. Os que, pelo contrário, mostravam sinais evidentes de recuperação, obtinham alta depois de serem lavados e trocadas as suas roupas.

Segundo o relatório, de um total de 828 pacientes, unicamente 288 $(34,78 \%)$ foram tratados no hospital. Entre eles, predominavam as mulheres $(54,16 \%)$, os menores de 30 anos $(76,04 \%)$ e os de condição livre $(92,96 \%)$. Dos hospitalizados morreram $134(46,52 \%)$, sendo a mortalidade maior entre os livres $(46,99 \%)$, frente a $40,90 \%$ entre os escravos; houve igual proporçáo para os dois sexos nas pessoas livres $(46,21 \%$ dos homens, $46,79 \%$ das mulheres), mas o índice foi muito maior nas mulheres escravas $(88,88 \%)$. De todos os pacientes morreram $423(51,08 \%)$, dos quais $31,67 \%$ faleceram no hospital.

\section{O FIM DA EPIDEMIA: BALANÇO DOS RESULTADOS}

A mudança do hospital para o "Moinho" representou o fim da epidemia. Mas se, nos últimos tempos, o tema da varíla tinha voltado a ocupar um lugar secundário e quase desaparecido dos debates da Camara, ao finalizar a epidemia, ele foi retomado com a promulgação de novas medidas. Algumas, ainda relacionadas com a epidemia passada, visavam concluir o esquema sanitário montado para combate-la. Assim, por exemplo, ordenou-se a caiação das casas dos doentes e o hospital. Paralelamente, começava uma ofensiva atuação de outra índole, visando o futuro, onde teriam efeito e significado; tratava-se de aproveitar a experiencia passada de modo a reverte-la, favoravelmente, para o município. De um lado, instituiram-se medidas sanitárias, normas, pautas de comportamento e mecanismos de controle e, de outro, estabeleceu-se uma versão dos acontecimentos para passar à história. Assim, a notf́cia do fim da epidemia causou "especial agrado" na Camara que resolveu publicá-la a fim de notificar a população.

Outros tipos de celebraçōes se sucederam, ao tempo em que se iniciou uma troca de elogios entre a Cámara e o Dr. Souza Alves recolhidas em 
SOTO, Cristina. Efeitos de ums epidemia de variola em Taubaté - (1873-1874).

oficios, nas atas da Camara ou nos relatórios e publicados pela imprensa ou em livros. Neles, a Camara cumprimentava e agradecia ao médico os serviços prestados; editou o seu relatório e, inclusive, deu o seu nome a uma rua, para preservar a memória da sua participação no combate à epidemia. Também congratulou outros que tomaram parte, citando os nomes, os méritos e o valor monetário aportado por cada um deles.

O médico, de sua parte, felicitou os outros que, como ele, tiveram uma atuação desinteressada e decisiva, incluída a Camara. E, por fim, ambos - a Camara e o Dr. Souza Alves - louvaram o caráter humanitário e cristão do povo de Taubaté, pelos donativos e demais atos de filantropia.

Em definitivo, proliferaram as congratulaçōes num clima de festa, em que se celebrava uma vitória. O discurso que permeou todos estes atos, apresentou a epidemia como uma ameaça sobre a cidade, que s6 foi vencida através da coordenaçäo de todos os esforços, após uma dura luta. Mas, alguns pontos nảo ficaram suficientemente esclarecidos: o que festejaram exatamente? O que foi vencido? Quem venceu e com que esforços? Quais pontos basearam a sua vitoria?

Na verdade, dependendo do enfoque, poderia se duvidar deste triunfo. Do ponto de vista médico, por exemplo, foi um fracasso se comparado com a média mundial na época, pois o indice de mortalidade nessa epidemia em Taubaté foi altíssimo. Na sua forma mais virulenta, muito incomum, a variola atingia uma mortalidade máxima de 20 a $50 \%$ da população, enquanto que a varfola suave apresentava uma faixa de mortandade inferior a $1 \% 11$.

Além disso, nem o tratamento dirigido para combater os efeitos colaterais parece haver sido totalmente eficiente, pois muitos morreram por causa deles ou por motivos simples, como por exemplo, de exaustão após 2 ou 3 dias de sofrimentos. $\mathrm{E}$ sem falar dos que morreram de outras doenças: reumatismo, febre tifoide, pneumonia.

O tratamento mostrou que, na verdade, não seria preciso um hospital senāo para isolar, reunir e facilitar a tarefa do doutor: no mais, ele poderia ter sido aplicado nas proprias residencias dos pacientes. Apesar do surto haver se apresentado "de modo assustador" ${ }^{12} \mathrm{em}$ Queluz, nenhuma providencia foi adotada para evitar o contágio; a epidemia so começou a ser levada em

11 MANDEL, Oenld, o allia, Principal and Practice of Infections' Diseases. New Yort, Willy Metical Poblications, 1979. O proprio Dr. Souza Aves assinala: "Bm geral as epidemias no Brasil ainda se apresentam com o caráter devastados com que costumavam mostrar-se na Europa antes do virus vaccinico" (of Relatorio, p.12). 
R. Hbidorta, Sto Paulo, n. 127-128, p. 9-35, ago-dez/92 a jan-jul/93.

consideração com o passar do tempo, com o crescimento do número de doentes e, acima de tudo, não foram aplicadas vacinas suficientes, único modo de sanar a doença.

Fora a primeira petição, não houve mais solicitações neste sentido. $O$ médico também não demonstrou maior interesse e se, no fim do seu relatório, reconhecia a falta de vacina como causa principal da alta mortalidade, $o$ tom não foi, em momento algum, de censura à administração pública.

Por fim, quando a epiđemia cessou, não foram adotadas medidas a fim de evitar futuros surtos epidemicos e, quando estes surgiram, as atitudes continuaram identicas. Em 1884, por exemplo, "devendo se tomar providencias para que ela (a variola) não aumente (a Camara) indica que seja autorizado o Dr. E. Winther a escolher uma casa apropriada para um lazare to no subúrbio da cidade, para onde devam ser remetidas as pessoas que forem atacadas da moléstian"13.

Tudo parecia indicar a inexistencia de um verdadeiro interesse pela cura, como prova a história posterior da doença. As epidemias sucederam-se sem interrupção e, em 1969, o Brasil era dos poucos lugares no mundo em que ela ainda era endémica. A sua desaparição foi consequencia de uma campanha mundial de vacinação, e não de uma política nacional. $O$ último caso de toda América foi detectado no Brasil, em 1971, considerando-se mundialmente erradicada em $1979^{14}$.

Essa contradição entre a euforia das comemoraçōes e as deficiencias no tratamento aplicado, só pode ser entendida analisando-se a versăo das autoridades e o modo dela se apresentar. Neste sentido, os discursos médicos e administrativos mostraram numerosas coincidências.

Em relação à doença o discurso era sempre tranquilo, confiante, objetivo e explicativo. Esta era percebida como um fenómeno puramente material, físico e individual. À diferença da lepra, representada com um forte conteúdo moral, como um reflexo externo de fenomenos internos, a varfola foi definida com critérios empíricos e, neste sentido, "cientificos". Era ima-

13 Alas da Cammara de Taubate, 15 sessło ordinária, 23 de novembro de 1885, p.214.

14 MANDELL, G., et alii, op. cit.,p.986. 
SOTO, Cristina. Efeitos de uma epidemis de varfola em Taubate - (1873-1874).

ginada como um vírus que, entrando no organismo humano, produzia uma série de sintomas, internos ou externos, característicos e fáceis de se identificar. Tais sintomas desenvolviam-se segundo um curso medicamente previsivel, produzindo moléstias colaterais e desembocando na cura ou na morte, dependendo exclusivamente da relação do doenté com o seu quadro clínico.

Os pacientes, de acordo com este ponto de vista, constituíam-se apenas nos organismos nos quais a doença se produzia e proliferava, podendo ser divididos em função de suas respostas à doença e suas reações aos cuidados médicos. Nesse raciocínio, o doente era o principal e quase único responsável pelo desenvolvimento e o desfecho final da doença; além de também sé-lo pela sua contraçăo.

Segundo essa concepção, tanto a doença quanto o doente eram fenomenos individuais, não sociais, e muito menos económicos. Assim, acabaram sendo extraídos do seu contexto de origem, citado unicamente quanto às suas condiçóes higienicas e à densidade de população; todavia, era uma interpretaçáo que so completava a anterior sem a contradizer, porque esses fatores ambientais contribuiam à propagação da doença mas não a produziam; a responsabilidade era da população, que se aglomerava, e não observava os devidos cuidados higienicos.

Mas se os lugares mais populosos, mais sujos e mais afetados pela varfola, eram também os mais pobres, ficava então o pobre associado à sujeira e à varíla e, enquanto portador e propagador de doenças, caracterizava-se como socialmente perigoso. A doença constituia mais um atributo da pessoa pobre e nāo o produto de uma situação de miséria. Seguindo essa imagem, a atenção médica foi dirigida ao corpo onde, em última instancia, se encontrava a solução; de modo preventivo, buscou-se promover a urbanização para evitar a existencia de focos de infeç̧ão, mas nunca fomentar uma polftica de reformas sociais, no sentido de questionar a pobreza ou de aliviar as condiçōes de vida desta parte da população.

Na verdade, porém, a varíola é uma enfermidade intrinsecamente unida às condições materiais; sua frequência e tipo dependem do grau de imunidade da população, atacando e propagando-se sobretudo entre os mais debilitados fisicamente e com menos defesas biologicas ${ }^{15}$.

Segundo esta concepção e à diferença da lepra, o contágio era um fenômeno físico, concreto, tangível e conhecido. Sendo, então, admitida a

15 Assim por exemplo, na Europa durante o seculo XIX, a variols esteve presente quase exclusivamente entre o operariado e nos partos (cf. Mandell,G., p. 985). 
R. Htstórta, Săo Paulo, n. 127-128, p. 9-35, ago-dez/92 a jan-jul/93.

possibilidade de uma intervenção humana para frear sua propagaçăo, através de medidas claras, objetivas e reais. Contudo, conhecer a forma de transmissão não significava a desaparição do perigo, por isso que este aspecto do contágio era o mais temido, onde a enfermidade se apresentava ameaçadora, pois podia se transformar em epidemia.

Neste ponto, o discurso dava um giro para adotar um outro tom; carregado de conotações também de ordem moral, tomava um vocabulário emprestado aos discursos religiosos ou militares, acumulando imagens que faziam referencia a outras experiências. Com a epidemia, a doença se transformava, de um fenómeno físico, individual, localizado, conhecido e sob relativo controle, em um fenomeno de dimensão social, cheio de símbolos e significados, intangiveis, indefinidos, ambíguos, que esboçavam problemas e soluçóes de outra indole.

A epidemia variólica era vista como uma ameaça externa que se estendia sobre o município, entendido no sentido de "comunidade", isto é, um perigo comum que afetava a todos igualmente. Possura também o caráter de expiação típica das epidemias, pois servia para testar a preparação, a resisténcia e as virtudes da população e dos seus administradores. E não se tratava de uma simples doença: a cidade era visitada pela propria morte, a representação de uma luta entre dois agentes, a vida e a morte, nos corpos de seus habitantes, que eram assim "flagelados". A epidemia era um "hóspede incómodo" que se instalava na própria casa, desafiando as defesas, invadindo a intimidade; uma "semente" que depositada, permanecia oculta, inimiga, para depois germinar traiçoeira, rápida, "vorazmente", sem dar oportunidade para se precaver da surpresa. "Germem" infecto e infeccioso, representava, acima de tudo, a essência do todo negativo.

O discurso se tornava, portanto, inseguro, subjetivo, deixando transparecer entre outros sentimentos, o temor. Era o temor dos sãos perante os enfermos, dos vivos frente aos mortos. As atitudes assumidas desde a primeira medida, quando se solicitou ajuda em dinheiro, tinham a intençăo de prevenir e năo de curar os já afetados; o tratamento e a forma de apresentar a doença, denotavam uma preocupaçáo maior para com os não atingidos do que para com os contagiados. Era o medo do contágio em um município percebido como um todo organico, em que uma parte insana ameaçava estender-se pelo resto; preocupaçăo que começava a se revelar na medida em que esta possibilidade se tornava real com o aumento da epidemia.

Mas ainda assim, a possibilidade de um verdadeiro contágio parecia remota. Como o próprio doutor manifestou, ela concentrou-se nas zonas mais baixas e insalubres, entre os mais pobres. Alem disso os numerosos doentes foram isolados no hospital, não circularam livremente pela cidade propagando o seu mal; foram segregados, levados longe, fechados e seus contatos limitados aos mantidos com outros doentes e os empregados do estabeleci- 
SOTO, Cristina. Efeitos de uma epidemia de varfole em Taubate - (1873-1874).

mento. Todavia, aqueles que puderam, fugiram com as suas famflias para as fazendas, incluindo-se os próprios vereadores. Por fim, era uma doença que se espalhava só por contato pessoal e direto (principalmente nas residencias, casas e nos hospitais) entre pessoas pouco imunizadas ${ }^{16}$.

Detrás desse temor ocultava-se outro mais difuso e de rafzes mais profundas e que nascia da apreensão de determinados grupos perante a proximidade de outros, num espaço físico e socialmente, menos definido do que aquele da fazenda, perante a obrigatória convivencia na cidade com os mais pobres. A epidemia era mais uma forma em que se manifestava e se concretizava esse outro medo.

Considerando a epidemia desta perspectiva, as medidas adotadas pelas instituições públicas adquirem outro significado: a epiđemia não pressupunha um momento de grande sofrimento dos moradores da cidade, mas sim uma quebra đa rotina e da ordem; portanto, as medidas públicas nāo visavam o doente em especial: comportavam a visão do são e a ele buscavam atingir. Isto explica a demora para uma reação imediata e efetiva do surto, ou mesmo - fato de as autoridades celebrarem o final da epidemia, apesar de ela ainda continuar em alguns bairros. Neste caso, a preocupação não era terminar com ela definitivamente, mas evitar que infeccionasse de novo a cidade, isto $e$, determinados bairros.

Durante todo o tempo, não se tratava de extinguir a varíola senāo de recuperar o que eles consideravam um grau satisfatório de ordem; por isso, as medidas se limitaram ao momento em que, devido às proporçōes atingidas, os mecanismos normais de controle se revelaram insuficientes para garantir os limites da ordem.

Esta alteração se manifestou em vários sentidos: a epidemia subentendia uma quebra da rotina, desde o momento em que uma parte da população estava doente, outra fugida e o resto amedrontada. Provocava problemas na prática com relação à política urbanística, sanitária ou de limpeza, principalmente, por causa do crescimento do número de mortos e a insuficiência do cemitério provisório, o municipal não passando ainda de um projeto. Coloca-

idem. 
va problemas administrativos (responsabilidades, financiamento) que forçavam uma definição administrativa, um novo questionamento de competencias e funçōes, obrigaçōes e deveres entre todos. Em consequencia do surto epidémico, produziram-se deficiências no abastecimento de produtos de primeira necessidade, provocadas pelos atravessadores, apesar da regulamentação da Cámara, que tentou evitar a carestia comprando arroz e feijão para revender ao "povo", a preço de custo.

Contudo, o mais importante é que a epidemia evidenciou as falhas dos organismos municipal e provincial, as suas incapacidades administrativas, para prever e manter em limites reduzidos o surto epidemico e recompor o equilíbrio da sociedade: sua dependéncia económica; a sua falta de firmeza perante as pressōes dos atravessadores, as deficiencias de infraestrutura; a ausencia de um planejamento; as lacunas nas suas políticas urbanísticas e sanitárias (a carência de hospitais, cemitérios, serviço de recolhimento de lixo, ou esgotos); a falta de material e de pessoal especializado (por exemplo, de médicos ou pessoas preparadas para extrair o "cowpox" dos animais e aplicar nos doentes a vacina); as insuficiencias da política médica que punham em dúvida a capacidade pessoal do doutor Souza Alves e das possibilidades da Medicina; a existencia de miséria no interior da cidade e o desinteresse das autoridades, especialmente dos vereadores "refugiados" nas fazendas. Acima de tudo, a epidemia pode desmontar as imagens constiturdas desde o poder, e a auto-imagem do próprio município, o que poderia levar a população a questionar desde as polf́ticas seguidas pelos órgáos públicos atć o seu próprio poder.

As críticas à administração poderiam atrair desordens sociais ou protestos visando exigir mais responsabilidade e maior eficacia, e podiam conduzir à busca de outras alternativas ou soluçóes próprias por parte da população, como de fato aconteceu, com a procura de clínicas particulares ou curandeiros, a resistencia à hospitalização, a ocultação dos docntes e dos mortos. Desta maneira, era possível se subtrair do campo de ação da administração municipal num momento em que, no contexto de uma luta de poderes dentro do município, esta ação seguia uma política de ampliação de competências.

\section{O IMPACTO DA EPIDEMIA}

Desde a metade do século até o final, parecia crescer o interesse pela cidade e pela sua estruturação, coincidindo com a baixa produtividade do café. Já anteriormente, a elite dos fazendeiros possuia residencias urbanas, 
SoTO, Cristina. Efeitos de ama epidemia de varfola em Taubate - (1873-1874).

mas tudo girava ao redor da fazenda, unidade económica, polf́tica e social por excelencia.

Por este motivo e apesar da sua antigüidade, a cidade possura ainda numerosas questóes por resolver a nível de infraestrutura. A eles adicionavam-se os novos problemas que, sucessivamente, iam aparecendo, com a chegada das pessoas desmobilizadas da área rural, com a instalaçăo de fazendeiros, comerciantes, e, mais tarde, de migrantes, procedentes de outros paises ou outros pontos da Comarca.

A Camara, como principal 6rgão administrativo, ficou encarregada de organizar este crescimento. Todos os aspectos da cidade foram debatidos e decididos nas suas sessões; as atividades esportivas e recreativas, o ensino, a religlosidade, a saúde pública. Ela empossava os juízes e determinava quem seriam os médicos, engenheiros, professores, jornalistas e farmaceuticos que colaborariam com o Município, bem como as condiçōes salariais de todos os funcionários ou contratados; recolhia impostos e decidia quais as despesas a serem feitas; concedia ou desapropriava terrenos, construia estradas e organizava o transporte; regulamentava os lugares e condiçóes de venda; interferia nas associaçőes, clubes, irmandades e outras instituiçōes, na vida do quartel e na cadeia; relacionava-se com outras entidades fora do Município; possuia poderes para conceder licenças, assinar contratos, legislar e modificar os códigos de posturas e a utilização da Força Pública.

Dentre todos estes aspectos, o da higiene adquiriu, com o tempo, maior relevancia e peso nos debates; organizar e limpar tornaram-se sinónimos, sendo impossível a existência deles separadamente. A cidade, por exemplo, năo podia considerar-se em ordem, sem um bom serviço de coleta de lixo ou a presença de animais vagando pelas ruas.

Organizar significava, basicamente, que cada atividade e função se desenvolviam no lugar que lhes correspondia por prévia determinação, ou seja, no lugar "apropriado". Por outro lado, significava que a cada lugar deveria corresponder uma funçāo, o que presupunha a desapariçāo de zonas amorfas ou indefinidas. Neste sentido, um depósito de lixo num quintal abandonado estava fora de contexto, atentando contra a ordem por significar sujeira.

Ainda mais, o que determinava se o uso de um espaço estava mais ou menos apropriado, eram os critérios higiénicos, mais do que os critérios estéticos.

Por outro lado, a limpeza também era entendida como sinónimo de higiene (o deposito de lixo era anti-higienico porque podia provocar problemas de saúde, doenças) e, em consequência, a ordem ia ser determinada pelos critérios sanitarios. Estes estavam por detrás da preocupação pela extinção de 
R. Htstorta, Sao Paulo, n. 127.128, p. 9-35, ago-dez/92 a jan-jul/93.

formigueiros, pela limpeza de ruas, praças, chafarizes, cadeia, ou casas de comércio; por detrás da decisão de mudar, para lugar "remoto e apropriado" o lixo, para um espaço mais "remoto e cómodo" a cadeia e para outro mais "conveniente" o cemitério; pela remodelação dos esgotos e das feiras, pelo fechamento dos animais soltos nas áreas urbanas do Município.

Além da visão físico-espacial da ordem, existia também interesse pela ordem social da qual a física é indissociável, sendo frequentemente um reflexo desta. Não se tratava unicamente de remover os lixos, de criar um espaço para a venda e de retirar os mendigos da rua; pelo mesmo motivo deveriam ser afastados os doentes que, fora do lugar apropriado, desafiando a ordem, podiam transmitir e provocar doenças.

Em 12 de janeiro de 1864, "o Sr. Monteiro (vereador) requereu providéncias contra o grande número de morféticos arranchados na estrada, com grande perigo de contágio pela reunião dos nossos escravos com aqueles doentes e servidáo das águas de que logo pouco distante fazem uso vários habitantes desta cidade ${ }^{\mathbf{1 7}}$. O problema năo foi resolvido e, em 1874, coincidindo com o surto da varíla ainda o Sr. Assiz Moura indicou que "se promovesse os meios ao alcance da CAmara, afim de fundar-se um hospital para serem colhidos os lázaros que em abundância vagam pelas ruas da cidade $^{18}$. Dentro da ordem estabelecida, não ficara reservado um espaço para eles. Como tudo o que não se encaixa e, assim, ameaça alterar a ordom definida, eles deviam ser mantidos afastados 19 . Da mesma maneira, os lugares propícios ao contágio da varíola deveriam ser isolados e fechados.

De uma forma geral, tratava-se de determinar os limites, as fronteiras da cidade, para evitar irrupções descontroladas, procedentes do exterior, na forma de mercadorias contrabandeadas, pessoas indesejáveis, ou germes infecciosos; tentava-se isolar, "imunizar" a cidade, tornando-a um lugar seguro; paralelamente, concentraram-se os esforços de controle ou de "aformoseamento' do interior urbano, expulsando-se o residual. Visava-se em suma, criar uma cidade esférica, sem impurezas, fechada, sem contradiçбes,

17 Atas da Camara de Taubate, 12 de janciro de 1864, p.265.

18 idem, 21 de julbo de 1873, p.139.

19 O afastamento fisico é paralelo ao esquecimento (que se perpetua apon a cura) a dratituicfio de todas as simbolos de identidade, ao abandono, à assistęncia negligente e so tratamento mbellos exiremamente rigoroso. Medidas perpetuadas att boje (caso do leprosirio de Finpitingur) qus ignorando a origem e forma de contígio e consequientemente o rembetio, atributio um excesso de periculosidade ao doente, nåo justificávej do ponto de viste da mediclon, perecern ortentudas a punir e alo determinadas a obter a cara. 
SOTO, Cristina. Efeitos de uma epidemia de varfola em Taubate -(1873-1874).

formando um todo. A limpeza era uma manifestaçăo externa e um símbolo deste projeto; o critério sanitário seria, então, de importância capital na hora de estabelecer hierarquias sociais, competências, classificações.

Ao tempo em que o fator sanitário adquiria relevancia, a figura do médico ocupava maior espaço no ambito público e aumentava a sua influencia, bastante presente em múltiplas áreas.

Ele já constituía uma figura importante por causa da escassez, no Vale do Parafba, de médicos ou de hospitais, sendo Taubaté um dos primeiros e únicos Munićpios a possuir um hospital ${ }^{20}$. Recebia consideraçāo como pessoa admirada e associada à elite, como figura política e membro da Camara Municipal, como sujeito de prestígio cuja opinião era manifestada e escutada em todo lugar, principalmente, através da docéncia nas clínicas ou hospltais, nas sociedades médicas, nos artigos dos jornais.

Cumpria também uma função essencial dentro do aparelho judicial. Na sua qualidade de perito em casos de violencia, ele constatava defloramentos ou mortes, a gravidade do crime e, consequentemente, da sua análise dependeria a sentença final. Extra-oficialmente, ele difundia o seu parecer sobre o caso, influenciando juízes e membros do júri e decidindo diretamente no veredito, como participante do júri. Enfim, ele determinava o grau de periculosidade ou loucura dos criminosos.

Às vezes, o seu prestigio vinha da participação em alguma atividade economica, mas é principalmente no exercf́cio da sua profissảo que ädquiria a sua autoridade; ele julgava o nível de gravidade de uma doença e, ao mesmo tempo, do enfermo; determinava quais as roupas, os alimentos e as condiçőes habitacionais adequadas à saúde; decidia através de atestados médicos quem estava suficientemente são para trabalhar, ou quem devia recorrer à caridade.

Estas atribuiçðes foram sendo consideravelmente ampliadas, na medida em que a política sanitária foi se tornando indispensável. Como doutor, vereador ou encarregado da higiene pública definia quais eram os lugares insalubres, quais as situaçōes ou atitudes que podiam gerar doenças, examinava as águas ou as carnes locais, julgava quais eram os perigos que uma determinada doença apresentava para a sociedade e as resoluções precisas; determinava quais eram as prioridades de higiene e de urbanização. Ele opinava sobre a localizaçāo do cemitério e do hospital, as condições apropriadas de sepultamento, a conveniência ou năo de um tipo de construção e a exata distribuiçáo interna dos prédios... 
R. Flstórta, S6o Paulo, n. 127-128, p. 9-35, ago-dez/92 a jan-jul/93.

Como médico municipal, ele se encarregava do "tratamento e curativo das pessoas pobres ${ }^{21}$ ", proporcionando dados estatísticos sobre seu número e características, hábitos, condições de vida e, finalmente, convertia-se em um importante instrumento de controle social. Todas essas atribuições tornavamse evidentes e reforçadas em tempo de epidemia. Ao médico correspondia alertar sobre o perigo e, uma vez caracterizado como epidemia, impedir a sua propagação.

É nesse contexto que se produziu a aliança entre as autoridades médicas e as admininistrativas. As duas apresentavam o mesmo interesse pelo controle de algumas parcelas do corpo e da mente da população do Município; ambas visavam obter a sua obediencia e confiança; tentavam, igualmente, exercitar o seu direito de interferir na liberdade individual do cidadāo, em prol do bem comum. A fim de monopolizar esse direito, precisavam, de uma parte, ganhar a aceitação da população persuadindo-a da necessidade e eficácia da sua gestāo e, por outra, necessitavam neutralizar os concorrentes. $E$ isso era especialmente válido no caso do médico, dado que os fundamentos da ciencia médica pressupunham o monopólio do saber médico nas mãos dessa instituição, pois o seu poder provinha da sua condição de possuidora da verdade no terreno da saúde. $O$ depoimento de Otavio Freitas (médico pernambucano do começo do século) a este respeito, é altamente esclarecedor: "O médico, mesmo calouro como eu era, não tinha o direito de dizer que "não sabia", de confessar sinceramente que "hesitava" e, por isso, "necessitava meditar um pouco". Ele seria, naqueles anos de fim do século XIX, um profissional perdido, se externasse tal pensamento à maioria dos clientes. Seria "um incapaz", um "inhábil para a clínica", um "teórico", sem o menor valor $^{22}$.

Mas como a verdade era uma só, qualquer outra prática paralela na área de saúde estava errada e, como em outros casos, tinha de ser excludda, apagada, desqualificada. Isso inclura curandeiros, não facultativos, boticários que receitavam, comadres e, inclusive, eclesiásticos que, até então, exerciam um certo domínio sobre as questões relativas à doença e à morte.

Atas da Câmara de Trubate, 6 de outubro de 1873, p.149. Ao seu pedido fol nomeado "Modico do Partido da Câmara".

22 O depoimento deste médico, apesar de pertencer a uma outra Epoca e lugar, é de grande valia por ele ter sido um importante medico sanitarista. Entre outras realizagoses levoo a cabo uma grande campanha contra a varfola e dirigiu por 30 anos o primeiro Instituto de Pesquisa e Aplicaçáo de Variola. Freitas, O., Minhas Memórias de Médico, Såo Paulo, Cla. Ed. Nacional, 1940, p.106. 
SOTO, Cristina. Efeitos de uma epidemia de varfola sni Taubate -(1873-1874).

De fato a resistencia perante a intromissão médica era forte e ainda iria persistir durante muito tempo. A procura de curandeiros, ervateiros 23 , comadres $e$, em geral, de pessoas que inspirassem uma maior confiança ${ }^{24}$, enfim, as soluçőes populares, ainda exerciam forte pressão e concorrencia à eficiencia e ao saber da medicina academica.

A luta dos médicos pelo poder também estava presente dentro da sua própria instituiçăo. Existiam conflitos entre os diferentes métodos, entre os médicos mais velhos e os mais jovens, aqueles identificados com as formas mais tradicionais, esses detentores de um conhecimento mais recente; os primeiros, mais ligados ao tratamento costumeiro e os segundos, conectados ao saber erudito dos livros; os médicos do interior e os das grandes cidades...

A epidemia aumentava a possibilidade de se criar divisóes entre os médicos responsáveis e de se dar preferência ao controle de cada indivíduo sobre seu próprio corpo e a sua vida. Em suma, a epidemia revelou uma crise em um contexto de organização, definiçāo, classificação, e na procura de modelos de convivencia e de mecanismos de controle, que bem poderiam aprofundar a descrença ou, pelo contrário, poderiam contribuir à formação de sólidas bases, na estrutura sócio-municipal da regiāo.

$\rightarrow \infty$

Neste contexto compreende-se que as medidas adotadas foram dirigidas aos sadios e objetivavam recompor a ordem; ante o temor do contágio físico, opóe-se o isolamento dos doentes do resto da população, da sua rotina, casa, famflia, objetos, trabalho, etc, visando, assim, manter a epidemia dentro

23 Ate boje, vendem-se acs domingos ervas medicinais no mercado de Taubaté e đăo-se instrugües pare o seu consumo.

24 Geralmente os médicos eram observados entre as classes populares com desconflança ou recejo, preferindbese pessoas mais proximas a seu universo mental e ambiental. En o temor que tinha suas ratres en seculos de experiência de convivio com epidemias e com atitudes repressivas, estigmatzadoras, segregadoras, discriminatbrias e punitivas, contra os afetados pela variola. Temor perante medichs provenientes de figuras e instituiçoses remotas que, longe da realidade dos doentes, tentsvam dirigir suas vidas. Em 1942 aconteceu um caso extremo que evidenciou esea atitude. A operária Benedita Amaral, ao constatar que estava gravida, tomou numerosos remedios para abortar ficando doente mas, negou-se a avisar ao métioo, escolhendo os cuidados de uma parteira, apesar das recomendaçoes desta para recorret ao metico diante da sua impotência. No processo que se seguiv à sua morte, o métioo acuson injustamente a parteira de ter causado a morte pela sta ignorancia. Processo Crime, Taubate, 1942. 
R. Hist6ria, Sao Paulo, n. 127-128, p. 9-35, ago-dez/92 a jan-jul/93.

de limites geográficos, numéricos e temporais. Opuseram-se tambem as medidas higiennicas, como a obrigação de caiar as casas e o hospital e outras para evitar a acumulação dos mortos, de lixos, de águas.

Todavia, os dois tipos de atitudes se revelaram insuficientes para persuadir os doentes a colaborarem com o esquema; eles resistiram à hospitalização e à assistencia médica, interpretando-os como mecanismos de controle, meios de disciplinar, desrespeito à sua intimidade e ao livre arbitrio; negaram-se a se afastar dos seus lugares, correndo talvez o risco de sofrer, de contrair uma outra doença, de morrer em desacordo com as suas crenças e cultura, e de serem sepultados sem se observar as medidas convencionais e necessárias aos vivos $\mathrm{e}$ aos mortos.

De fato, a maioria dos doentes não foi tratada no hospital. Quando is to aconteceu, a Camara recorreu à força, cumprindo as solicitaçöes do médico e do delegado de polícia, também vereador ${ }^{25}$.

Diante dos problemas administrativos criados pela epidemia, as instituições opuseram uma atividade coordenada de todas elas. No tema da responsabilidade, a explicação da Camara foi a de que os principais culpados pela propagação foram os doentes e a população que não observava as necessárias medidas higiénicas. Eram eles que provocavam uma situaçăo conflitiva que precisava ser resolvida. Portanto, os diversos poderes (público ou privado, municipal ou provincial, médico ou administrativo, civil ou eclesiástico) sentiam-se moralmente compelidos pelos seus sentimentos humanitários e caridosos a intervirem, mas não consideraram que isso fazia parte das suas obrigaçōes.

No terreno financeiro, e seguindo o costume de epidemias anteriores, a Camara declinou de toda responsabilidade, exigindo do Governo Provincial - envio de recursos humanos, materiais e monetários. Este, no entanto, também não assumiu totalmente a responsabilidade: a sua resposta foi esporádica, ocasional e precária. Mesmo assim, financiou parte da operaçáo através do seu Chefe do Polícia e a troca de uma informaçăo minuciosa sobre os acontecimentos. Em última instância, o Governo Provincial reservou-se a capacidade de tomar as principais decisões e de marcar as diretrizes a seguir; alertando sobre os principais perigos (ao seu ver, os curandeiros e os cemiterios). Completando suas doaçōes, coube aos fazendeiros, ordens religiosas e

Em 23 de março de 1874, partiu do delegado a solicitaça para o "emprego de mectidus endrgicas afim de evitar a continuaça do contagio da presente epidemia". Foi o primeiro peclido nette sentido. Atas da Câmara de Taubaté, 1874, p.167. 
SOTO, Cristina. Efeitos de uma epidemia de variola em Taubate - (1873-1874).

ao Presidente da Camara, a título pessoal, arcar com as despesas, de modo que o problema econômico resolveu-se mediante uma ação conjunta de governos e instituiçōes, públicas ou não.

Na área da organização da campanha anti-epidêmica ocorreu também a mesma resposta múltipla, característica de uma situação de indefinição de competéncias, submetendo-se a responsabilidade principal ao médico e encarregando-se a Câmara da coordenação e dos assuntos burocráticos.

Em geral, todas as medidas visavam tranquilizar tanto a população quanto os proprios dirigentes, neutralizar possíveis criticas, oferecendo uma imagem de eficácia de uma administração preparada racional e cientificamente. Quando as medidas citadas não foram suficientes para atingir esse efeito, os agentes públicos auxiliaram-se de um poderoso agente - a propaganda - para difundir uma visão dos fatos e da sua atividade em relação ao acontecido. Nela, eles se apresentaram como os salvadores do Município: sua intençăo adquiriu maior destaque quanto mais intensas foram as proporções da epidemia, e tanto mais caracterizadas como um perigo; neste caso, o discurso sobre a epidemia e o discurso sobre eles mesmos tornaram-se complementares. E por isso que a epidemia foi representada como algo que irrompia subitamente, desenvolvia-se e acabava por ser vencida quando, na verdade, houve uma grande continuidade. A varíola era uma doença endemica continuou a se-lo ainda durante muito tempo, e esta epidemia foi mais um dos surtos que regularmente apareciam. Nesse mesmo ano de 1873 já haviam aparecido alguns casos no mês de janeiro e continuou a apresentar doentes nos bairros periféricos, mesmo depois de ser declarado o fim da epidemia, no mes de agosto.

A iniciativa médico-governamental foi também apresentada como um serviço de utilidade pública, desde o momento em que a epidemia constituía um mal que afetava toda a comunidade. Mais ainda, era definida como uma atuaçăo voluntária, desinteressada, "animada de boa vontade" e de sentimentos humanitários; eram "atos filantrópicos" e de caridade, impelidos pelo sentido de dever moral, próprios de uma "afanosa missãon" ${ }^{26}$. No caso do médico esta característica era ainda mais acentuada. Para ele, a sua profissão representava uma espécie de sacerdócio, onde o médico estava destinado a cumprir uma alta missão, quase heróica, eliminando numerosos inconvenientes e obstáculos, acudindo a toda solicitaçāo feita a qualquer hora do dia ou da noite. Era um dever acima da sua vontade. Havia também um componente

Relatsria op. cit. 
R. Hlst6rta, Sao Paulo, n. 127-128, p. 9-35, ago-dez/92 a jan-jul/93.

sagrado que conferia ao seu realizador qualidades e virtudes superiores aos seus olhos e aos olhos dos outros.

O objetivo, do médico como também dos outros poderes, era semear o bem, "socorrer aos desvalidos", "mitigar as dores dos pobres", atender aos "gemidos da pobreza", "amparar os desvalidos da sorte" 27.

Essa imagem coincidia com a que o Dr. Otavio de Freitas manifestara anos depois ao tratar de características inerentes à profissão. Os médicos constitúam-se "sacerdotes de uma das mais nobres profissōes", o ser médico significava, para ele, o ato de "colocarmos o anel auriverde no dedo indicador e sairmos de casa em casa semear o bem, a revigorar ou, pelo menos, a consolar os que sofrem, enchendo as nossas arcas de agradecimentos e de afeições de todos os tamanhos, vendo-nos cercados de grandes consideraçóes e de carinhos e, sobretudo, (para que nega-lo?), ricos, profundamente ricos, em virtude da profissão rendosa que abraçamos..."

Mais concretamente, diante de uma epidemia (neste caso a febre amarela surgida no interior de São Paulo em 1892) explicava: "fomos todos nós cheios de entusiasmo, fortes na luta a travar contra a doença e a morte, demasiadamente confiantes de tudo vencer sem dificuldades e sem canceiras, afugentando o mal e enchendo, em pouco tempo, as cidades devastadas, de intensa vida, desta exuberante vida de que estávamos saturados em nossa adolescência e que pensávamos poder fornecer, as mãos cheias, aos milhares de vítimas da desumana epidemia...". E continuava rememorando: "Era bem de conjecturar o trabalho insano que nos aguardava, mas, nem um só momento fomos invadidos pelo desánimo. Pois que! Sacerdotes amanhã, da grande religião de Esculápio, havíamos de deixar transparecer desfalecimentos aos primeiros embates?..." 28 .

Mas esta imagem, que se acabava transferindo a toda a profissăo médica, só era justificada se acompanhada de um serviço gratuito aos pobres. De outro modo resultava difícil acreditar no seu desinteresse, como no caso do Dr. Souza Alves que dirigia uma clínica privada e realizava outras atividades menos altruístas. Assim construía-se uma imagem baseada nas atividades filantrópicas que pretendia abraçar a totalidade de aspectos da profissåo médica quando, na realiđade, era só uma parte dela.

Junto com essa imagem, o médico adotou, em todo o relatório, um tom de falsa modéstia, desculpando-se pelos erros cometidos. No entanto, cm momento algum ele reconheceu, explicitamente, alguma falha havida na sua

27 idem.

28 FREITAS, O., op. cit. pp.53, 81, 83, 87. 
SoTO, Cristina. Efeitos de uma epidemia de varfola em Taubaté - (1873-1874).

geståo. Pelo contrário, no discurso, não havia lugar para a dúvida, pressupunhs-se que o seu conhecimento e a sua prática eram verdadeiros, cientificos e infaliveis. \$6 no parágrafo final admitia algo, mas logo contraposto pela sua boa intencionalidade. "Não desconhecemos as muitas faltas havidas: umas dependendo de nossa imperícia, outras inamovíveis. No entanto, restanos a satisfaçăo de tranquilamente poder dizer -quod potui feci ${ }^{20}$.

Diante de uma atividade tão desinteressada e bem intencionada, não cabia aos receptores propor nenhuma critica e, ainda menos, exigir nenhum direito. Apresentando a doença fora do contexto e os seus portadores como responsáveis, a epidemia como uma ameaça, um agente destruidor da normalidade, instaurador do terror e do desespero, a intervenção médica como providencial e os próprios médicos como salvadores, conseguia-se neutralizar as criticas e encobrir as faltas da administraçāo. As autoridades saíram triunfantes, satisfeitas, cheias de autoconfiança, da prova a que tinham sido submetidas.

Da perspectiva das autoridades a epidemia foi um exito e proporcionou motivos suficientes para justificar as celebraçōes posteriores. Ainda mais, a epidemia foi para eles um fenomeno positivo, do qual todos saíram beneficiados. Médicos, Camara, Governo Provincial, Chefe de Polícia Provincial, ordens religiosas, vigário, delegado de polfcia, fazendeiros, farmacêuticos... Todos usufrufram do prestrgio de terem restaurado a ordem. Todos eles demandavam a sua parcela no agradecimento que a população thes devia prestar. Ao farmacéutico o médico queria "recomendá-lo à gratidão e reconhecimento deste Municipio"; o presidente da Camara se fez "credor de público reconhecimento"; também "merecedor dos maiores encomios o digno fornecedor, que gratuitamente se prestou a tão laboriosa tarefa: nunca poupando esforços, sempre animado do melhor zelo e dedicação para cabal desempenho de sua afanosa missão" ${ }^{30}$. O médico "jamais mostrou um momento de desânimo ou cansaço", "sempre pronto, levando a generosidade até

30 Idem, pp2 2. Palsuras do metico. 
R. Hbtónta, Sto Paulo, n. 127-128, p. 9-35, ago-dea/92 a jan-jul/93.

o sacrifício, a abnegação até o heroísmo, ninguém fez mais do que ele, ninguém o igualou" 31 . E assim por diante.

Mais do que isso, a epidemia serviu para estreitar a aliança entre todos os poderes. $O$ médico prestou um serviço à Camara e esta retribuiu-lhe, o vigário complementou quando a atuação médica fora insuficiente. A polícia ajudou na tarefa de persuasão. A epidemia reforçou, principalmente, a uniăo existente entre a iniciativa privada e as instituiçōes públicas.

Paralelamente, cada um deles saiu reforçado. Para a administraçăo municipal o combate à epidemia representou o triunfo de uma polftica dirigida ao pobre, já que tratava de neutralizar suas potencialidades mais perigosas, ao invés de melhorar suas condições de vida. Significou também o triunfo de uma concepção na qual o pobre era visto como merecedor de caridade, e não um sujeito com direitos próprios.

Por outro lado, ao criar a imagem do inimigo comum tentavam obter um consenso e uma uniāo em torno das instituiçöes públicas e dos poderes privados. Não obstante, apresentando a epidemia como um fenomeno que se espalhou a todo o Município, apesar de ela ter afetado seletivamente a sociedade e do tratamento haver sido diferencial, ocultavam as divišós sociais existentes.

Além disso a epidemia acelerou o processo de definição de competências. A administração municipal também deu um passo na sua pretensāo ao monopólio do poder, pelas mãos das instituiçōes da saúde pública e da assistencia aos pobres. Por fim, a epidemia confirmou a política sanitária que estava sendo adotada e, com ela, um tipo de ordem e uma forma de dominação.

O Dr. Souza Alves também saiu reforçado em vários pontos. Como em todas as situações de emergencia e crise, acionaram-se medidas excepcionais que não teriam sido propostas em outras situaçðes e, is to the reportou beneffcios. Para acabar com a varfola, a Camara delegou ao médico essa responsabilidade; concedia-lhe "ilimitada confiança", com uma atitude que se assemelhava a um ato de fé, e conferia-lhe para isso poderes excepcionais, que lhe permitiam atuar em vários setores: administraçăo pessoal das finanças recebidas, liberdade para criar o hospital e recolber os pacientes, dirigindo o seu funcionamento e estrutura, o tratamento dos doentes, o lugar e condições de sepultamento. Ao substituir o "panico" pela tranquilidade reve-

Idem, Prólogo. Palavras da Camara. 
SOTO, Cristina. Efeitos de uma epidemia de varfola em Taubate - (1873-1874).

lou-se mais uma vez figura essencial no ambito administrativo o que the aumentava o poder na esfera pública. Mostrando a existencia de uma distribuiçăo espacial das moléstias em função do grau de higiene, demonstrava a necessidade de uma polf́tica urbanista sob a orientaçäo de um médico sanitário.

Seu poder na área médica também aumentou. $O$ cargo de médico municipal e, mais tarde, de diretor do hospital o destacaram de outros médicos locais. Mas, sobretudo, a partir de sua posiçāo privilegiada ele pode infringir um grave dano aos seus competidores. De fato, em seu relatório, ao mesmo tempo que eliminava qualquer, dúvida que pudesse ser levantada sobre o saber médico, ele desqualificava os que tratavam a doença sem as devidas credenciais: a "descomunal brutalidade e extravagancias charlatanicas", o "charlatanismo e a ignorância pretenciosa". Fora do saber médico, todos estavam errados e, por isso, também eram perigosos, podendo provocar desgraças. Os conhecimentos dos competidores sobre plantas medicinais eram apropriados, mas não se thes reconhecia aos seus possuidores nenhum valor. Ao mesmo tempo, ele também usava as plantas mas ignorando as práticas as quais estavam associadas (utiliza para acalmar as dores ou fechar feridas mas nåo para dar boa sorte, por exemplo). Admitia suas propriedades curativas, mas lhes negava qualquer conteúdo simbólico. Todavia, uma estrita separação de saberes acontecia muito mais no discurso do que na prática cotidiana, pois o médico era influenciado pelas práticas locais tanto como o ervateiro o era pela literatura médica.

Também dentro do terreno médico, saiu reforçada a corrente de pensamento que ele representava, inovadora e conectada às idéias do exterior, em detrimento de outras posturas locais, por ele consideradas amiúde ignorantes, frutos de um excessivo apego à tradição.

Náo obstante ter prestado serviços gratuitos, o Dr. Souza Alves também iria usufruir economicamente da epidemia. Desde o momento em que sua profissáo estava submetida às leis de mercado, à oferta e à procura, um aumento do seu prestígio profissional poderia ter repercussōes quanto ao aumento da clientela na clínica particular, por exemplo. A relaçăo da profissăo médica com o mercado, foi bem colocada pelo Dr. Freitas, num esclarecedor parágrafo:

"A medicina, apezar dos pezares, tem, sob certos pontos de vista, um aspecto comercial no seu modo de agir, como profissto liberal e, por isso, os seus cultores -sacerdotes convictos mesmo que eles sejam -nāo podem prescindir deste mercantilismo que lhes proporciona, no final de contas, o ganha-pão necessário à sua subsistência. 
R. Htstorta, Sto Paulo, D. 127-128, p. 9-35, ago-dea/92 a jan-jul/93.

Tal aproximação económica é que determina a classe médica procurar os mesmos pontos de preferencia, escolhidos pelos comerciantes, para montagem de seus consultórios.

Uns e outros carecem de clientes ou de freguezes, como se queira denominá-los, para o exercício das profissöes que executam; os médicos nos seus consultórios e os negociantes em suas casas comerciais ${ }^{\text {n2 }}$.

A epidemia oferecia também a oportunidade de aumentar os conhecimentos médicos e reformulá-los para uso no futuro, através dos dados estatísticos e da experiencia hospitalar. O hospital constitula uma escola, onde se aprendia com a experiéncia em doentes. O Dr. Souza Alves aplicou, sucessivamente, e com maior ou menor suceśso, novos remédios e teorias que depois debateria com outros colegas. Por fim, junto com o seu prestígio o médico sempre ganhava uma presença muito maior na sociedade.

Do ponto de vista sanitário, ele escolheu dentre várias possibilidades, a solução mais antiga, aquela que escolhia uma instituição onde prestar assistência ao pobre, mas que afastava e isolava o doente, separando a doença do contexto social. Não visando necessariamente a cura e menos ainda a prevenção, a estrutura endémica, sócio-económica e cultural da doença permanecia inalterada.

A introdução do esquema hospitalar que o médico apresentou como única alternativa - "indeclinável necessidade" - e a consecução do apoio e do dinheiro necessários representaram o triunfo de uma proposta médica e de uma concepção sobre o doente.

O esquema da antiga instituição foi substituído por uma organização hierárquica baseada na vigilancia, onde a confiança no enfermeiro era mais importante do que o seu conhecimento ou atitudes profissionais e onde o relacionamento com o paciente tornava-se distante, racional e escasso. Junto com a reforma administrativa modificaram-se as condutas dos pacientes, transmitiam-se-lhes noçōes sobre saúde, limpeza, disciplina corporal, hábitos alimentares, asseio no vestir e, inclusive, valores morais. Em suma, induzia-os a tratar do seu próprio corpo de uma nova maneira, vista como

32 FREITAS, O., op. cit., p.100. Na mesma posiç̧⿰亻 se encontrava o farmactutico que dependia da licença da CAmara para abrir uma loja. Passada a epidemia ele solicitou da Camara um atestado pelos servigos prestados durante a crise. 
SOTO, Cristina. Efeitos de uma epidemia de varlola em Taubaté - (1873-1874).

mais responsável e apropriada. Através do hospital o médico irrompia no imaginário dos enfermos, nos seus tabus, tentando acabar com as suas apreensōes e implantar uma nova visảo. Quando tudo isso apresentava-se insuficiente, sempre era possível recorrer à força, complemento indispensável de toda persuasão.

Nas suas açōes, o médico revelava as suas preferéncias por um tipo de ordem social, enquanto que através delas tinha a oportunidade de moldar a sociedade. De todos os motivos expostos deduzia-se que a epidemia era também uma oportunidade e um instrumento. Novos estereólipos foram criados e confirmados os já existentes, todos eles com um forte conteúdo simbolico, no qual a epidemia era usada como sinónimo de đesordem.

Nesse contexto, as medidas finais adotadas pela Camara adquiriam sentido: reforçavam o lado simbólico, criavam imagens, veiculando uma versão apologética, ocultando e distorcendo, com o discurso, a realidade. Elas eram o último degrau de uma série de medidas que dava sentido ao acontecimento e construía uma memória coletiva dos fatos.

\section{BIBLIOGRAFIA}

Atas da Camara de Taubate (1869-1879), Felix Guisard Filbo (Ed), Sao Paulo, Empresa Editora Universal, 1944.

ABREU, M.M., "Aspectos do Folclore em Taubaté", Taubaté, Prefeitura Municipal de Taubat6, Taubateana, 7, 1980.

BRRTOLLI FILHO, C., Epidemia e Sociedade. A Gripe Espanhola no Municipio de São Paulo, Disserţçåo de Mestrado, Depto. de História Social, FFLCH-USP, Såo Paulo, (mimeo).

CASTORIADIS, C., A Instituiçäo Imagindria da Sociedade. Rio de Janeiro: Paz e Terra, 1982.

CHAMBERLAIN, M., Old Wives Tales -Their history, remedies and spells - Great Britain : Virago Press Ltd, 1981.

DELUMEAU, J., $O$ Medo no Ocidente, 1300-1800. Uma Cidade Sitiada. Såo Paulo: Companhia das Letras, 1989.

DOUGLAS, M., Purity and Danger, Londres, Routledge and Kegan Paul, 1966.

DUBY, G., As Tres Ordens ou o Imaginario do Feudalismo. Lisboa: Editorial Estampa, 1982.

FREITAS, O., Minhas Memórias de Médico, Săo Paulo, Rio, Recife, Porto-Alegre: Companhia Editora Nacional, 1940.

FOUCAULT, M., Mictofísica do Poder, Rio de Janeiro; Ediçöes Graal, 1979.

MANDEU, G.; Douglas, R.G.; Bennett, J., Principal and Practice of Infection's Diseases. New York: Willy Medical Publications, 1979. 
R. Htstórła, Sšo Paulo, n. 127-128, p. 9-35, ago-dez/92 a jan-jul/93.

(

MARSIGLIA, R.G., "Medicina Social: Evolução de um Campo de Idéias e de Práticas", Temas IMESC, Soc. Dir., Saúde, Săo Paulo, V.I (1), 1984, pp. 3-11.

MILLET, S., "Os Intimas da Morte", in: Roteiro do Café e Outros Ensaios, 4 ed., Sáo Paulo: Hucitec, 1982.

PEREIRA, J.C., "Problemas Sociais e Problemas de Saúde Pública", Temas IMESC, Soc. Dir., Saúde, Sø̆o Paulo, V.4 (1), 1987, pp.5-20.

Relatorio Apresentado a Camara Municipal de Taubaté pelo Dr. Antonio Teixeira de Souza Alves, 11 de setembro de 1874; Taubaté, Typ. do Paulista de Alfredo de Almeida, 16 de novembro de 1874.

ROWLAND, R., Antropologia, Historia e Diferença, Porto, Ed. Afrontamento, 1987.

SHORTER, E., A History of Women's Bodies, England, Penguin Books, 1984.

SONTANG, S., A Doença como Metaffora, Rio de janeiro: Ediçós Graal, 1984.

TRONCA, I., "A Questăo do Imaginário na Prática do Historiador", Anais 2 Congresso Latino de História da Ciência, Nova Stela, 1989, pp. 275-277.

TRANTER, N.L., Population and Society, 1750-1940, Londres: Longman, 1985.

ABSTRACT: Trying to understand the contradiction detected between the measures applied by the authorities in the combat to a smallpox epidemic which arose in 1870 in the municipality of Tanbetf and the subsequent celebrations, this article will uncover the local self-interest, the rising importance of sanitary criteria in the orientation of the municipal policy, the proposal toward the fear which the disease stirs up, the resolutions destined to neutralizing the conflicts derived from the epidemic and the process of elaboration of an official version of the facts. From the interrelation of these factors, the meaning of the event is extracted.

KRY-WORDS: Epidemic, Patarba Valley, Hygiene, smallpox, urbanization. 